\title{
Spatial Patterns Associating Low Birth Weight with Environmental and Behavioral Factors
}

\author{
Donal $^{1}$, Hartono ${ }^{2}$, Mohammad Hakimi ${ }^{3}$, Ova Emilia ${ }^{4}$ \\ ${ }_{1,3,4}$ Faculty of Medicine, Universitas Gadjah Mada, Indonesia \\ ${ }^{1}$ Department of Health in Murung Raya, Central Kalimantan, Indonesia \\ ${ }^{2}$ Faculty of Geography, Universitas Gadjah Mada, Indonesia
}

\begin{tabular}{l} 
Article Info \\
\hline Article history: \\
Received Jan 06, 2017 \\
Revised Feb 21, 2017 \\
Accepted Feb 28, 2017 \\
\hline Keyword: \\
Low Birth Weight \\
Environmental Risk Factors \\
Health Behavior \\
Spatial Analysis \\
Mercury Contamination
\end{tabular}

Article Info

Article history:

Received Jan 06, 2017

Revised Feb 21, 2017

Keyword:

Low Birth Weight

Health Behavior

Mercury Contamination

\begin{abstract}
Low birth weight (LBW) is a significant public health problem in the world. It was estimated globally by the World Health Organization (WHO) that prevalence of LBW was 15\% of all births. In Murung Raya district LBW cases remain high. This paper aimed to identify and discuss the relationship between environmental risk factors with LBW in Murung Raya.A spatial analysis was conducted with 150 women as the total participantswho were recruited through the incidence data in 2013-2014. The questionnaires, medical records, and geographic data were measured by Stata software, ArcGis, SatScan, and Geoda. The study results indicated there was significant correlation between health behavior and environmental variables with the strength of external neighborhood effect across LBW risk factors. More intense clustering of high values (hot spots) was found through the spatial analysis showing that most of the cases were located near the defined buffer zone. This research demonstrates that the spatial pattern analysis provided greater statistical power to detect an effect that was not apparent in the previous epidemiology studies.
\end{abstract}

Copyright () 2017 Institute of Advanced Engineering and Science. All rights reserved.

\section{Corresponding Author:}

Donal,

Department of Health in Murung Raya,

JL. Let.Jend Soeprapto Puruk Cahu 73911 Kalimantan Tengah, Indonesia,

Phone: 62528 31897, Fax. 6252831896.

Email: donal@mail.ugm.ac.id

\section{INTRODUCTION}

Newborns with LBW (<2,500 grams) develop slowly mostly having poor health outcomes and approximately 20 times greater risk to die than heavier babies. There are more than 20 million newborns worldwide and the level of LBW in developing countries was $16.5 \%$, which is more than twice the rate in developed countries. The level of LBW in Indonesia in 2013 was 10.2\%. It has not decreased to expected rates. While in Murung Raya, Central Kalimantan, Indonesia, the rate of LBW was $9.5 \%$ in 2013, and it has increased to $10.6 \%$ steadily since 2014 [1]. This fact suggests that LBW remains a challenging public health issue in both the national and district levels.

Beside maternal history of previous delivery, other widely identified risk factors of LBW are environment and behavioral factors [2]. The identification of clusters, buffer zones, autocorrelation, nearest neighbor, and Getis-ord General G with higher LBW risk can hypothesize the pattern, function, and effect of risk and disease etiology [3]. However, the association between spatial patterns with personal and social risk factorswith LBW is difficult to establish because the exposure of determinants can occur at any level over a long time period making difficult the determination ofcausal relationships.

This study is spatial analysis as a set of methods useful when the data are spatial [4], for all manipulations of spatial data carried out to improve one understanding of the geographic phenomena that data represents [5], normally have spatial analysis tools for feature statistics or geoprocessing, with the types 
are used vary according to subject areas [6]. The studyof spatial analysis of LBW in Murung Raya has never been done before. This study aims to find out the relationship between environment and health behavior determinants of LBW by spatial analysis. Murung Raya district was classified into several sub districts based on their level area to examine the potential area disparity in LBW rates.

The outcomes gleaned from this study are necessary to providespatial data of LBW in Murung Raya and to identify the relation between the variables of area and health behavior as risk factors of LBW to better establish theframework for planning health promotion programs, prevention and intervention activities targeted to specific geographic regions and high-risk populations in Indonesia.

\section{RESEARCH METHOD}

\subsection{Study design}

This study used spatial analysis study designs. It was conducted from August to December 2015 in six sub-districts of Murung Raya, i.e Murung, Tanah Siang Selatan,Sei Babuat, Seribu Riam, Tanah Siang, and LaungTuhup. The survey instruments used for this research included questionnaires as primary data, with medical records, geographic data, and reports of mercury pollution as secondary data. The total numbers of participants, 150 women were matched with age, parity and residence. They were recruited at the primary local health center at Puskesmas through a record search among the data charts from 2013-2014, with inclusive criteria for 75 women with LBW delivery as the study case group and 75 with normal delivery as the control group. Incidence of LBW was measured by Poisson Regression, Spatial Autocorrelation (Global Moran's I), Getis-ord General G (z score Gi), Average Nearest Neighbor tool (NNI tests), the space-time permutation model, buffer (analysis), and diagnostics for spatial dependence. Spatial statistic studies examining LBW were done using software Scan Statistics, Geoda, Arcgis, and Stata.

\subsection{Sample and data collection}

Sample of this study was the mother with live birth inMurung Raya District.The inclusion criteria of the subjects were all live births listed in Health Department of Murung Raya District's database 2013-2014. The database was compared with the data of the primary health center and the midwive'smedical records. There were 150 subjects included in this study. The number of case-control was 75 LBW and75 controls. Types of matching criteria included age, parity, and resident. The case criterion was mothers with babies with live birth weight $<2,500$ gram and the control criterionwas with live birth weight $\geq 2,500$ grams.

\subsection{Measurement}

Data about health behavior determinants, i.e Traditional Birth Attendant(TBA) care, Ante Natal Care (ANC), drinking рора (10-17 \% alcoholic Dayak's ethnic traditional beverage, was made by fermented rice for a ritual ceremony drinking) [7], smoking, and accessibility to primary health care facilities were obtained from interviewing themothers. Environmental determinants were slope surface, altitude, and mercury exposure.

\subsection{Statistical analysis}

The descriptive analysis involved matching of age, parity, and residency. Poisson regression analysis for Incidence Rate Ratio (IRR) with significance level at $\mathrm{p}<0.05$ was performed with Stata version 12. The scan statistical method based on the discrete Poisson probability model was employed in this study to detect district clusters of high of LBW rates [8]. GeoDa was used to find out Moran Inndex/Degree of Freedom (MI/DF) through the diagnostic of spatial dependence [9], ArcGis provided measures of Spatial Autocorrelation (Global Moran's I), Getis-ord General G (z score Gi), Average Nearest Neighbor tool (NNI tests), and Buffer (Analysis) [10]. Data was further analyzed with Poisson regression IRR tests for significant statistical correlations.

\section{RESULTS AND ANALYSIS}

\subsection{Results}

\subsubsection{Descriptive statistics}

Descriptive analysis of characteristics of mother with sample matching age, residence, and parity was found with sum of samples $75 \mathrm{LBW}$ and 75 control were adequate TBA care total 32 cases $(82.05 \%)$ and 7 controls (17.95\%), inadequate ANC 33 cases (71.74\%) and 13 controls (28.26\%), drinking popa with total cases $16(84.21 \%)$ and control $3(15.79 \%)$, smoking $21(82.21 \%)$ and controls $9(30 \%)$, and difficult accessibility total cases $63(55.75 \%)$ and controls $50(44.25 \%)$. The characteristics of the mothers with environment variables based on slope surface involved most of the cases with under slope surface $<2 \%$ total 
$50(66.67 \%)$ and slope surface $6-10 \%$ only $4(5.33 \%)$. Most cases involved variable altitude $<60$ meter with $47(62.67 \%)$, and $>500$ were $3(4 \%)$. The variable mercury exposure was at level 0.0144/0.0172 about 24 $(16 \%)$, and at level $>0.0425$ were $4(2.67 \%)$. Based on the altitude, most of mothers tended to live at lower altitudes $<60$ meter were $47(\%)$, and a few at the highest altitude $>500$ meter were $3(4 \%)$. Acoording to slope surface data most of the residents of the cases were $<2 \%=50(66.67 \%), 2-4 \%=16(21.33 \%), 4-6 \%=$ $5(6.67 \%)$ and $6-10 \%=4(5.33 \%)$.

\subsubsection{Spatial autocorrelation}

The result of global spatial autocorrelation was based on proximity factors between each subdistricts' estimated linkages to LBW rate. To determine the relationship between sub districts linkages used global autocorrelation with five categories MI. The number of LBW in Murung Raya sub districts was obtained in Tanah Siang Selatan/Sei Babuat MI=0.759, Laung Tuhup MI=0.315, Saripoi MI=0.2, and Murung MI=1.008, $\mathrm{p}<0.05$ and were found by Moran's Index to be positive, with only in Seribu Riam $\mathrm{MI}=0.470$ tended to be random. Spatial autocorrelation for variables ANC, TBA care, drinking popa, smoking and accessibility were all clustered as shown in Table 1 . This patterning indicated the presence of spatial autocorrelation within neighboring areas were more similar (positive) than expected resulting in nonrandom clustering.

Table 1. The Results of Spatial Autocorrelation with ArcGIS Case of LBW

\begin{tabular}{lccccc}
\hline \multicolumn{1}{c}{ Variabel } & Moran's Index (I) & Expected Index (EI) & z-score & $p$-value & exp. \\
\hline ANC & 0.514 & -0.016 & 14.595 & 0.000 & clustered \\
TBA care & 0.439 & -0.011 & 14.786 & 0.000 & clustered \\
Drinking popa & 0.558 & -0.056 & 4.967 & 0.000 & clustered \\
Smoking & 0.587 & -0.036 & 5.535 & 0.000 & clustered \\
Accessibility & 0.505 & -0.009 & 19.127 & 0.000 & clustered \\
\hline
\end{tabular}

\subsubsection{Getis-ord General G Analysis}

Spatial analysis used Getis-ord General G Analysis. In the districts Murung $\mathrm{z}(\mathrm{G})=0.007$ and Seribu Riam $p>0.05$, the positive $\mathrm{z}$-score showing low values tended to be random in the areas of research, contrasting with the sub districts Tanah Siang Selatan/Sei Babuat $z(G)=0.114$ that tended to be low clustered. Tanah Siang $\mathrm{z}(\mathrm{G})=0.436$ and Laung Tuhup $\mathrm{z}(\mathrm{G})=0.822, \mathrm{p}<0.05$ showed high values and tended to be high clustered. Spatial analysis used Getis-ord General G Analysis for variables ANC, TBA care, drinking popa, smoking and accessibility were all high clustered as shown in Table 2.

Table 2. The Results of The Analysis of Spatial Statistical Models Getis-Ord General G with ArcGIS

\begin{tabular}{lccccc}
\hline \multicolumn{1}{c}{ Variable } & Observed General G & Expected General G & z-score & p-value & Exp. \\
\hline ANC & 0.230 & 0.230 & 3.017 & 0.003 & High Clustered \\
TBA care & 0.175 & 0.175 & 3.926 & 0.00008 & High Clustered \\
Drinking popa & 0.211 & 0.211 & 2.636 & 0.008 & High Clustered \\
Smoking & 0.145 & 0.145 & 1.913 & 0.056 & High Clustered \\
Accessibility & 0.152 & 0.152 & 4.336 & 0.00002 & High Clustered \\
\hline
\end{tabular}

\subsubsection{Nearest Neighbor Analysis}

To identify the distance among cases LBW was analyzed by nearest neighbor analysis. The sub districts Laung Tuhup NNI= 1.84, and Saripoi NNI $=1.33$, p value $<0.05$, which means that the pattern will be clustered, while in the sub districts Murung NNI=0.36 and Seribu Riam NNI=0.68, and Sei Babuat/Tanah Siang Selatan NNI=0.751, appeared as random dispersed patterns. Variable ANC, TBA care, drinking popa, smoking and accessibility were clustered $(\mathrm{NNI}>=0$, p value $<0.05)$ as shown in Table 3 . The $\mathrm{z}$-score was given to all variables. This result means that there was less than $1 \%$ likelihood that this clustered pattern could be the result of random chance.

Table 3. The Results of The Nearest Neighbor Analysis with ArcGIS

\begin{tabular}{|c|c|c|c|c|c|c|}
\hline Variable & $\begin{array}{c}\text { Observed Mean } \\
\text { Distance }\end{array}$ & $\begin{array}{c}\text { Expected Mean } \\
\text { distance }\end{array}$ & $\begin{array}{c}\text { Nearest Neighbor } \\
\text { ratio }\end{array}$ & z-score & p-value & Exp. \\
\hline TBA care & 0.003 & 0.027 & 0.117 & -15.846 & 0.000 & clustered \\
\hline Smoking & 0.017 & 0.042 & 0.398 & -6.199 & 0.000 & clustered \\
\hline Accessibility & 0.004 & 0.024 & 0.198 & -16.304 & 0.000 & clustered \\
\hline
\end{tabular}

Spatial Patterns Associating Low Birth Weight with Environmental and Behavioral Factors (Donal) 


\subsubsection{Clustering Analysis}

The result of clustering analysis as shown in Table 4 identified in 2013-2014 from purely spatial analysis scanning for high incidence rates using the Poison model found a statistically non significant cluster ( $p$ value $>0.05$ ) comprising two sub districts in Murung Raya with three cases of LBW in sub district Murung that were observed with 0.50 expected case and the cluster had relative risk of 6.00. While inTanah Siang Selatan and Sei Babuat had a most likely cluster that had 2 cases of LBW with 0.44 expected case and high relative risk of 4.50. A second statistically not significant cluster also was identified in another area. Although the other clusters were presented statistically not significant, still their relative risks were high.

Table 4. Clustering LBW

\begin{tabular}{llccccc}
\hline \multicolumn{1}{c}{ Area } & Type & Numberof cases & Distances $(\mathrm{km})$ & Expected case & RR & p-value \\
\hline Murung & Cluster 1 & 2 & 3.21 & 0.50 & 6.00 & 0.91 \\
& Cluster 2 & 5 & 1.63 & 0.52 & 5.71 & 0.98 \\
TSS / Sei Babuat & Cluster 1 & 2 & 7.17 & 0.44 & 4.50 & 0.308 \\
\multirow{3}{*}{ Joloi } & Cluster 2 & 2 & 0.032 & 0.67 & 3.00 & 0.811 \\
Tanah Siang & Cluster 1 & 2 & 0.02 & 1.20 & 1.67 & 0.66 \\
& Cluster 1 & 3 & 4.37 & 0.55 & 3.67 & 0.248 \\
Laung Tuhup & Cluster 2 & 2 & 5.72 & 1.64 & 1.83 & 0.931 \\
& Cluster 1 & 2 & 0.33 & 0.44 & 4.50 & 4.50 \\
& Cluster 2 & 2 & 0.25 & 0.67 & 3.00 & 0.915 \\
& Cluster 3 & 2 & 0.28 & 0.89 & 2.25 & 0.995 \\
\hline
\end{tabular}

\subsubsection{Buffering analysis}

Buffering analysis as shown in Figure 1 was used to determine the grouping of LBW cases based on the spatial element, in this case the distance from PHC with three distance categories. Most of the

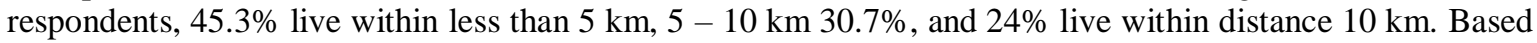
on the distance with health personnel with three distance categories, less than 20 meters $30 \%$, $44 \%$ of the respondents live in the category, 201-1,000 meters, and 26\% more than $1 \mathrm{~km}$.

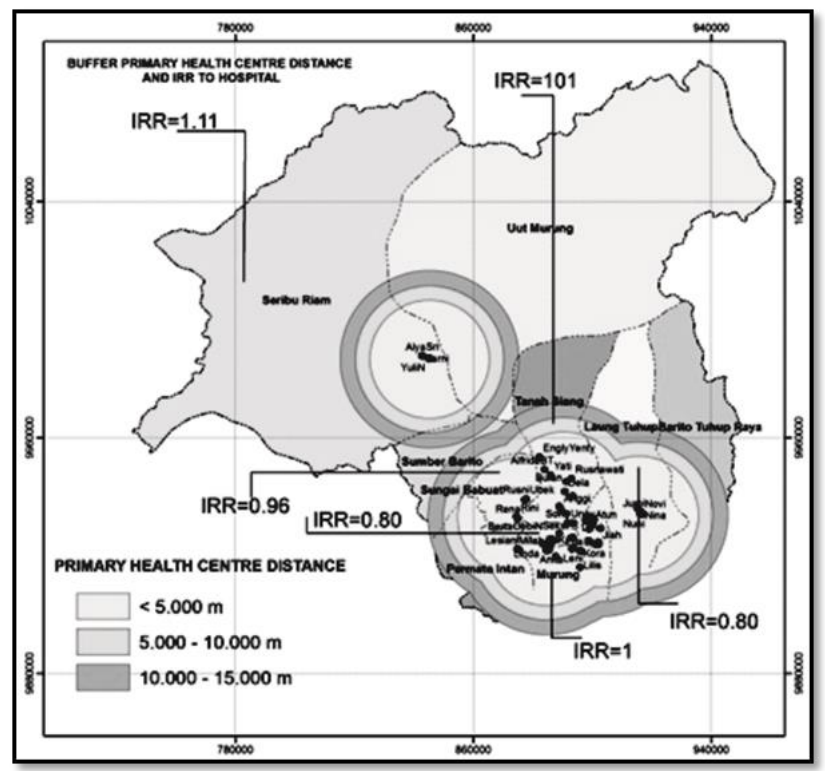

Figure 1. Buffer and IRR the Distance of PHC

\subsubsection{Diagnostic for spatial dependence}

Diagnostic for spatial dependence is shown in Table 5 used Geoda's software with several tests of spatial dependence, such as: Moran's I (error), Lagrange multiplier (lag), Robust LM (lag), Lagrange multiplier (error), Robust LM (error), Lagrange multiplier (Sarma). The test results (spatial lag models maximum likelihood estimation) were $\mathrm{MI}<1$, with $\mathrm{p}$ value $<0.05$, which means that $\mathrm{LBW}$ does significantly 
follow the pattern of spatial distribution. LBW is associated with factors that exist in the area or spatial distribution of LBW. From the test result the Lagrange multiplier with $p$ value $<0.05$ indicated that the spatial correlation does follow spatial patterning. The spatial lag models concluded that there was a dependency of spatial lag. This result means that there is a dependency between LBW cases in one area to other LBW cases in another area, so it can be continued to establish the SAR models. Lagrange multiplier test on spatial model error provided $\mathrm{p}$ values $>0.05$, which indicated that there was no spatial error so it was not necessary to format the Spatial Error Model (SEM). The model conclusion of alleged SAR produced a better parameter of the SER model in the case of spatial dependency in modeling of LBW in Murung Raya.

Table 5. Diagnostic for Spatial Dependence

\begin{tabular}{lccc}
\multicolumn{1}{c}{ Test } & $\begin{array}{c}\text { Subdistrict location } \\
\text { MI/DF }\end{array}$ & $\mathrm{Z}$ & P value \\
\hline Spatial Error Correction & & & \\
Moran's I & 0.034 & 2.25 & 0.024 \\
Lagrange Multiplier & 1 & 0.823 & 0.36 \\
Robust Lagrange Multiplier & 1 & 0.20 & 0.65 \\
Spatial Lag Dependence & & & \\
Lagrange Multiplier & 1 & 0.97 & 0.32 \\
Robust Lagrange Multiplier & 1 & 0.35 & 0.55 \\
\hline
\end{tabular}

\subsubsection{Poisson regression}

To detect the incidence of LBW the Poisson regression test was used to generate the number of cases expected in each environment exposure.An absolute measure of LBW risk was given by the Poisson regression, because the risks were dependent on the IRR of environment area variable. The Poisson regressions were used for the spatial analysis in this study because the probabilities of LBW in several sub districts at the event were rare.

Altitude variable used 7 categories of parameter value as shown in Figure 2. Altitude variable with $P$ value $<0.05$ was significantly correlated to LBW with all geographic altitude levels $(>100$ meters) in sub districts Tanah Siang Selatan (IRR=2.38), Sei Babuat (IRR=2.07), Joloi (IRR=6.09), and Saripoi (IRR=3.68). Mostly the residents of both cases and controls were at the altitude less than 60 meters above sea level, which are 95 respondent $(63.3 \%)$, but based on IRR pattern, the highest were 6.09 at sub district Seribu Riam with altitude 400-500 meters because the higher the respondent's residence, the higher the IRR value.

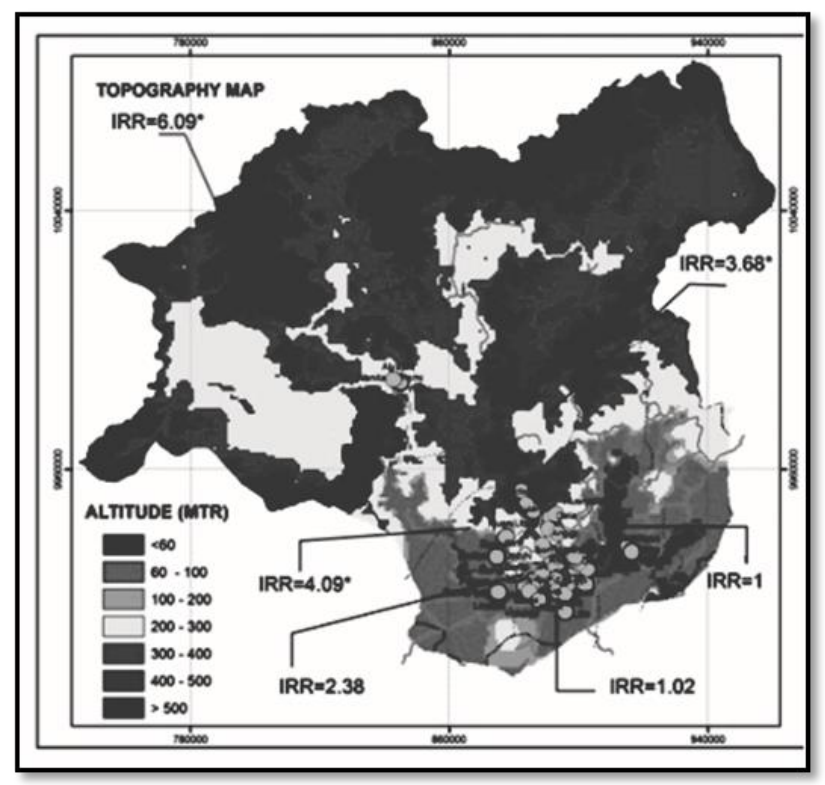

Figure 2. IRR of LBW According to Altitude

Slope surface is a relative measure of declivity on slope area toward the flat surface as shown in Figure 3. Variable slope surface correlated to LBW with the slope surface $(2-4 \%, 4-6 \%$, and >10\%) in sub 
district Seribu Riam (IRR=3.18) and Tanah Siang ( IRR=2.07). The characteristics of the analyzed respondent indicate that their residences are located at slope surface of $<2 \%$ meter, while LBW cases according to IRR showed the highest were 6-10\% located at sub district Seribu Riam because the higher the percentage of slope surface, the higher the IRR.

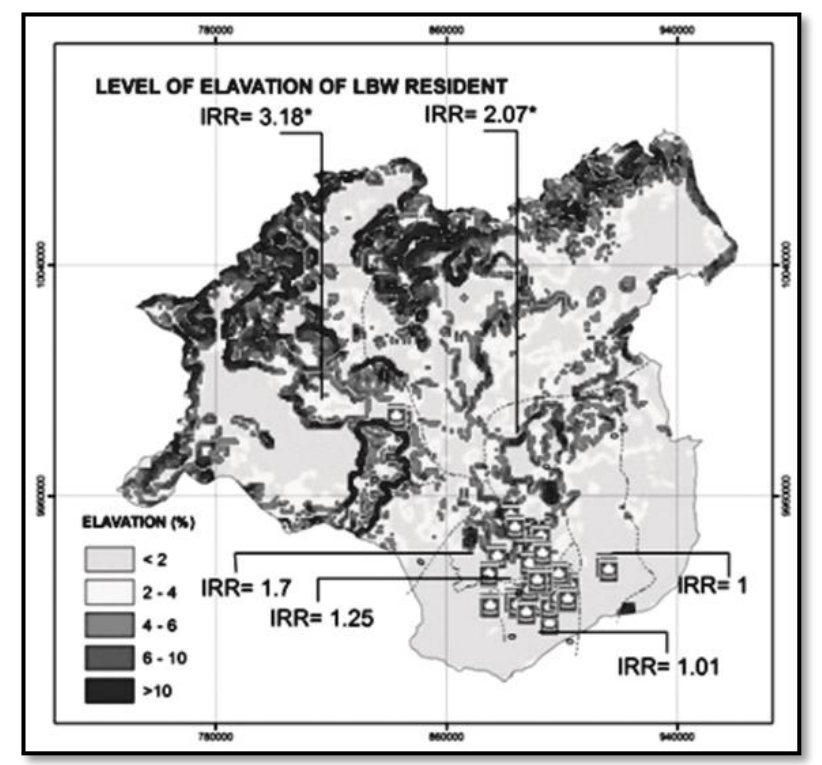

Figure 3. IRR of LBW According to Level of Slope

Mercury exposure was related to drainage area river basin condition and the number of case patients and control patients who lived in the area contaminated by coal and gold mining as shown in Figure 4. Mercury exposure correlated significantly to LBW with all levels $(<0.0143$ and $>0.0425)$ in sub district Tanah Siang Selatan (IRR=2.99), Sei Babuat (IRR=4.99), Murung (IRR=2.75), Laung Tuhup (IRR=3.19), and Saripoi (IRR= 2.99). The distribution of LBW cases based on mercury exposure for both cases and controls is mostly at level $0.0144-0.0172 \mathrm{mg} / \mathrm{L}$. The incidence rate indicated that LBW cases were mostly found at the center of the exposure and the IRR values were following the river flow.

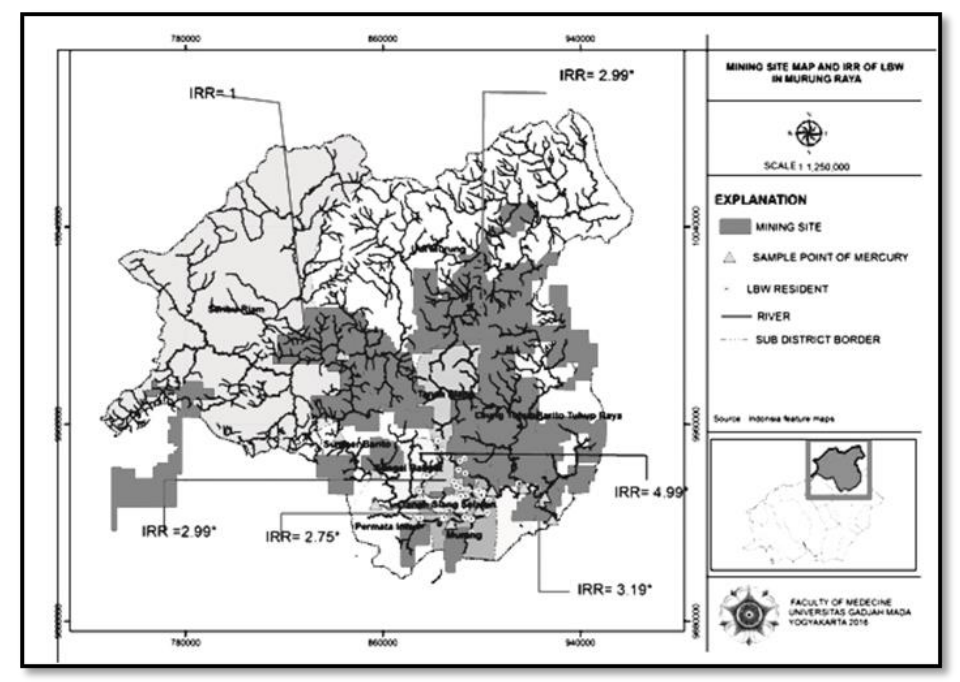

Figure 4. Map of Coal and Gold Mining Area Connected with Mercury Exposure 


\subsection{Analysis}

This study found that non adequate or without any antenatal care at all will cause many complications such as the increased incidence of LBW babies, compared with intensive adequate antenatal care, i.e. once at the first and second trimester, and twice at the third trimester. This result was in compliance with the theory of Chamberlain, G. \& Morgan, M. [11] in their book, The ABC's of Antenatal Care and the results of research in Washington that also found that LBW cases decreased after the enhancing of ANC [12], demonstrating that there are impacts of ANC to LBW [13]. It was also found that the dispersal pattern of antenatal variable was clustered, showing that there was a relationship between neighbor clusters with spatial features clustering and the occurrence of clustering. This result shared similar findings with other research utilizing spatial analysis to identify high risk pregnant mothers for intervention of antenatal visits by dividing the clustering at densely populated area [14]. The difference with this research was it involved areas where the populations were small with separated areas.

The habit of drinking popa before or during pregnancy was found in this research related with LBW risk. They tended to higher cluster (hot spot) with the establishment of dense clustering with individual neighbor relations with high IRR values in certain areas. This finding corresponded with the theory framework that was submitted by Kramer [15] in determining the prevalence of LBW that there were 43 factors that still need to be considered as LBW risk factors including alcohol consumption. This finding also corresponded with research on pregnant mothers showing alcohol consumption influenced the weight of the baby [16] (van Wijngaarden et al., 2014), where 26.3\% of LBW cases was caused by alcohol consumption during pregnancy [17], and alcohol was correlated with LBW risk [18]. Alcohol consumption of 12 times/day or greater increased the risk for low birth weight [19]. The results of these research continue to be a controversy since alcohol consumption was not directly related with LBW [20]. This finding also corresponded with research in Japan where the average alcohol consumption amount was 1time per day [21]. In this research, drinking popa was not an individual habit but it was one of the requirements from the local custom and traditional culture.

TBA care in this research influenced LBW because TBA provided treatment since the second month of pregnancy until the delivery process in traditional ways with the frequencies of visit more than 10 times compared with antenatal visits. This finding was in accordance with the theory that discussed social environment as a distal determinant that influenced LBW [22]. The TBA care procedures were not suitable with integrated pregnancy care standards, which are established by the government [23] mandating that pregnancy care should be handled by certified health personnel while TBA serves only as a partner. The finding in this research corresponded with several researches in sub-Saharan Africa and South Asia, which together account for over half of the deliveries $(57 \%)$ in the developing world, with up to $65 \%$ of births occurring outside hospitals and predominantly delivered by TBA care [24]. According to Geographic Weight Odd Ratio (GWOR) analysis results, $41.5 \%$ of birth by TBA indicated significant relationship in space with low level of education [25], while in West Africa more than $80 \%$ delivery process is handled by TBAs [26]. Recent research in Nigeria indicates that delivery process outside hospital tended to be LBW [20], showing spatially different levels of economic conditions between each family [27]. It should be admitted that every district with low levels of social economic condition always have TBAs to help pregnancy care through partnering with health personnel [28]. In this research TBA care was conducted in traditional ways.

Accessibilities are important components for a successful primary health care system. In this research we found that accessibility was related to distance, time travel and human resources with significant correlation with LBW risk, as mentioned in the theory of Anderson and Newman [29] that explained that accessibility was a support component for the communities using health services, and corresponded with the theory of service utilization [30]. Accessibilty factors clearly influence health services [31]. One of the methods to analyze the spatial accessibility is by calculating the measure based on geographic gravity. In this study the distance between community cluster and health facilities were used to calculate spatial accessibility. Recent research in Canada indicated the main problem of health service involved remote and rural areas where spatial access depends on cost, time travel, and distances [32]. Spatial accessibilities were dependent on a variety of factors including service place, time travel and distance, and location of health service to the needs of the communities [33]. The study determined that $12-14 \%$ of the communities suffered from lack of health services due to the distance to reach health personnel $>4 \mathrm{~km}$, distance to the hospital $>25 \mathrm{~km}$ and $<0.2$ mean distance (MD) individual every hour within a year [27]. The main problem in this research was nearly the same since the residences of the communities were located in remote areas that are far apart from other areas. Spatial access in this research related to the distance between sub district areas which indicated huge variation with almost $63 \%$ having difficult access, and only $12 \%$ with good access in the case groups. This result was similar with the research in Bhutan where $66 \%$ had difficult access and only $10 \%$ had good access [33]. This study found that the lack of the community needs toward the health services 
was due to their mobility as the consequences of their jobs and the presence of the health personnel was related with health personnel availability (supply) and community's availability (demand).

It has been found that there were linkages between sub districts' rate relationships. It was indicated by the presence of spatial autocorrelation within neighboring areas that are more similar (positive). It can be concluded that the similar characteristics between the cases have a + value or indicate that LBW among the cases in Murung Raya sub districts had a positive correlation among the near locations, and the same with the variables of ANC, TBA care, drinking popa, smoking, and accessibility providing important evidence regarding variability in the strength of external neighborhood effect across risk factors of LBW. Previous research indicated that the correlation might be positive or negative [30], but the occurrence of spatial autocorrelation was highly depending on the aggregation level [35]. This result was contrary with sub districts Seribu Riam who had a very low MI value, where it is also a near neighboring area. These results indicated that this variable has the fewest and weakest external neighborhood effect. It was also because this sub district has a very extensive region located at the upper end and the residents of the communities were not in one spread out areas, indicating that this variable has an intermediate external neighborhood effect [36]. The difference of the result in this research is that the external effects of the other examined variables were varied between medium to extreme. The possibility exists that the spatial pattern of this external might be shared by more than one variable.

This study with Getis-ord General G analysis found that the case of LBW in every sub districts had features with either high or low values clustered spatially with z-score negative, meaning that the smaller the $\mathrm{z}$-score the more intense the clustering of random value (cold spots), while some sub districts with the positive $\mathrm{z}$-score showing high value are clustered in the area of the research (random). Some sub districts and variables: ANC, TBA care, drinking popa, smoking and accessibility were correlated statistically significant, with positive $\mathrm{z}$-score, meaning that the larger the $\mathrm{z}$-score, the more intense the clustering of high value (hot spots). This result was similar with current health service strategies that targeted the location of the highest group of LBW cases [37]. The grouping based on health and environment behavior [9] and lowest value can be used to identify less served areas [38]. The difference of this study was we focused at the observed point of the hot spot which were the residences of the respondents with LBW cases and controls.

In this study analysis we focused at the point rather than the density of the dots in the study area to determine whether the point was observed with a range of NNI. Based on the calculation we found that the dissemination of cases of LBW in some sub districts had a spread random pattern and the others had a clustered case pattern. The variables of ANC, TBA care, drinking popa, smoking, and accessibility had clustered pattern. This result indicated the distance between one LBW cases with another nearest case. In relation with that mapping and the similar level of accessibility with no obstacle, this research indicated that the object observed in Murung Raya had the same correlation power showing that the nearest locations had different values and tended to be spread out. Similar with previous research, the cases were considered as dots in the study area with a clustered pattern [39]. This approach was also similar with other hot spots research [40].

Our results showed some non statistically significant and secondary clusters found in this research in the observed area within sub districts were related to environmental and behavioural variables. The smoking variable as a statistically significant cluster was only found in Murung Raya Districts, while in other sub districts all clusters had more high relative risk and tended to have LBW. Significant clustering results were similar with [41] whose research was based on similarity using Global Moran's I, showing non significant spatial clustering GWR. Theoretically the same feature of observed group pattern is caused by clustering [42]. In this research we found clustering resulted with high relative risk, which tended to cluster in each observed group. Clustering also was used to identify LBW groups using individual cases [43], thus geographically being able to set the consequenses to nearest neighbor areas [44], and generating spatial mapping data concerning the association regarding social and economic risk factors [37]. Spatial clustering results describe and explore spatial patterns from one spatial cluster to another nearest spatial cluster along the river [45]. This clustering did not occur in Murung Raya District due to the observed area being very wide and every residential area was constrained by the forest or the hills area. One of the requirements of clustering was grouping in one spread out area without any constraint. This approach to clustering was in accordance with the theory that the total coverage of the area can directly affect to their clustering area [46].

Buffer analysis in this study was used to identify the distance from PHC and health provider with the residence of LBW cases. In this study, the unit of buffering was the point of PHC and resident of health provider. Buffer operation refers to the creation of a zone of specified distance around the coverage features with 3 levels radius of distance. The research in Costa Rica indicated the following buffering was used to measure the distance between LBW: less than $1 \mathrm{~km}$ away from an outpatient care and $5 \mathrm{~km}$ away from the hospital. In terms of equity, $12-14 \%$ of population were underserved according to having an outpatient outlet within $4 \mathrm{~km}$ and the hospital within $25 \mathrm{~km}$ [27]. The potential spatial access to PHC also depends on the

IJPHS Vol. 6, No. 1, March $2017: 33-44$ 
patient's travel cost (time/distance) [32], in addition to the distance by buffering [47]. According to recent research buffering social capital-related variables have more impact on LBW [48], with buffering living within $200 \mathrm{~m}$ from major roads associated with a $46 \%$ increase in term of LBW risk. Mothers who live in buffer $8 \mathrm{~km}$ with fish consumption from the river were more at risk for LBW [49], and within buffers of 100 $\mathrm{m}, 300 \mathrm{~m}$, and $500 \mathrm{~m}$ of each maternal home and distance to a city park, the study found a statistically significant association between low surrounding greenness and full term LBW.

Spatial dependency analysis in this research at the non isolated sub district areas found that there were spatial dependency between LBW cases with variables of ANC, TBA care, drinking popa, smoking and accessibility. In the spatial lag model we concluded that there were spatial lag dependencies which mean that there were dependencies between LBW cases in one area with other areas. The model that was applied in this research to figure out the spatial influence in the data used the spatial auto regressive (SAR) model. This research approach was similar with the spatial dependency test or autocorrelation between the subjects observed and location [50],[51].

There was a significant relationship between environmental exposures of LBW. This study shows all districts have significant mercury contamination with high IRR, follow the stream, the altitude, and the slope [52],[53]. The process of environment exposure was because of the increased waste runoff carried by the rainfalls [54]. The contamination of mercury at the lower course of the river was higher than the upper course in sub districts. The result is in accordance with spatial risk valuation factors that decrease the gap of LBW influenced by environment exposure [55]. Environment factor was considered as a risk factor of LBW since it used the residence of mothers as a mediator of LBW [56]. Methyl mercury and heavy metals exposure were connected with LBW cases [16], This association also is revealed by the influence of geographical factors [57],[58]. There was further evidence for associations of Brome Hydragyrum (B-Hg) with decreases in birth weight [59]. Birth weight could be a predictor related to environmental contaminants and in a similar study in a river basin $\mathrm{B}-\mathrm{Hg}$ was found statistically significant [60].

Our study found that LBW mostly happened among women who were residing within 8 kilometer with fish consumption. The result of this research indicates that hair or blood concentrations are relatively higher among those who consume more fish rather than infrequent fish consumption [49]. Different results were found from the research in China that mentioned that was no significant associations observed between any heavy metals and birth weight [61]. The difference was because there were no tests conducted to check mercury level in the hairs or nails of contaminated mothers, and no research regarding the period of contaminations, their results are spurious and unsupported.

Mothers who lived in the highlands with lower oxygen level risked her baby for hypoxic fetal syndrome that causes neonatal asphyxia and LBW [62]. Differences were found in birth weight based on sexes and in the incidence of low birth weight depending on altitude [63], while the findings Tibetan birth weights are greater than those of other ethnic groups, both at high and low altitudes. Tibetans at low altitudes have heavier birth weights compared with Tibetans at high altitude. Birth weight that was lower at higher altitudes may be due to inadequate maternal oxygenation during pregnancy [64]. One study in South America found among the seven risk factors analyzed, altitude was the main predictor of birth weight [65].

This study found that the slope surface 4-6\% was significant as a risk factor for LBW in sub districts Seribu Riam and Saripoi, since both of the areas are located at high slope. The environmental characteristics are influenced by the slope surface and positively correlated with LBW [53]. These factors also may contribute to the role of maternal place of residence as a mediator of maternal stress and adverse reproductive outcomes among women [56].

From the analysis on the distribution of LBW relative to available hospital, we could visualize that only few areas were located beyond $12 \mathrm{~km}$ from the hospital in 2013-2014, but a significant relationship was found between distances to the hospital with IRR of LBW. Short distance neonatal transport was found useful and valuable for LBW infants with gestation age of 27-34 weeks in Southern Taiwan [66]. The population risk percentage for LBW was attributable to the distance from the hospital [67]. In Japan more LBW were found distributed within $30 \mathrm{~km}$ from a hospital with neonatology services [68]. These results show that the appropriate place of birth for LBW infants from low-income mothers may be influenced by the distance of their residence to an intensive care unit [69], but the distance did not contribute to the disparity in the use of top-tier hospitals [70].

\section{CONCLUSION}

The spatial analysis detected an effect for each of the seventy five cases of LBW that were included in the study, which were the number of case and control subjects that lived in different areas (isolated or unisolated area). It is apparent that the spatial analysis study provided greater power to detect the geographic effect of LBW. The spatial distribution of LBW in Murung Raya is far from even. In several cases the frequency of 
LBW in its district neighborhoods exceeds the statistical probabilities that could have arisen through random variation. This high incidence of LBW has also shown a significant relation to the spatial distribution of LBW. The crucial connection between incidence of LBW and geographic factor is particularly key to identifing behaviorial and environmental factors. Using the current evidence and theories examined, we concluded that the mapping of LBW by focusing on the neighborhoods using spatial analysis was useful for visualizing areas of LBW and this type of analysis could become a helpful tool for indicating the primary cause of the differences in LBW rates. The differences were best explained by examining spatial mapping of the variations in health behavior variables and environmental exposure characteristics.

\section{ACKNOWLEDGEMENTS}

This study was supported by Dinas Kesehatan Murung Raya, Kalimantan Tengah and Faculty of Medicine Universitas Gadjah Mada, Jogjakarta Indonesia. We would like to thank to them.

\section{REFERENCES}

[1] Dinkes Mura, "Profil Kesehetan Kabpaten Murung Raya 2014,” Dinas Kesehatan Kabupaten Murung Raya, 2015.

[2] Aguilera I., et al., "Association between GIS-based exposure to urban air pollution during pregnancy and birth weight in the INMA Sabadell Cohort," Environ Health Perspec, vol/issue: 117(8), pp. 1322-7, 2009.

[3] Grady S. C. and Enander H., "Geographic analysis of low birthweight and infant mortality in Michigan using automated zoning methodology," Int J Health Geogr, vol. 810, 2009.

[4] M. Goodchild and P. Longley, "The future of GIS and spatial analysis," 1996.

[5] O. Huisman and R. A. de By, "Principles of Geographic Information Systems An introductory textbook," Netherlands, ITC enschede, 2009.

[6] T. O. Sutton and M. D. Sutton, "A Gentle Introduction to GIS. Eastern Cape: Spatial Planning \& Information," Department of Land Affairs (DLA), 2009.

[7] C. Riwut, "Developing Culture and Nature in Kalimantan," Jogjakarta, NR publishing, 2007.

[8] Kulldorff M., "SaTScan_Users_Guide," 2015.

[9] Anselin L., et al., "GeoDa: An Introduction to Spatial Data Analysis," Spatial Analysis Laboratory Department of Agricultural and Consumer Economics University of Illinois, 2004.

[10] Esri, “Arcgis Spatial Analysis, Advanced GIS Spatial Analysis Using Raster and Vector Data," 2011.

[11] G. Chamberlain and M. Morgan, "ABC OF Antenatal Care, Fourth edition," London, BMJ Publishing Group, 2002.

[12] Chuku S. N., "Low Birth Weight in Nigeria Does Antenatal Care Matter," Institute of Social Studies, 2008.

[13] Nelson R., "Low Birthweights Spatial and Socioeconomic Patterns in Kamloops," Western Geography, vol/issue: 8(9), pp. 31-59, 1998.

[14] Chong S., et al., "Geospatial analyses to identify clusters of adverse antenatal factors for targeted interventions," Int $J$ Health Geogr, vol/issue: 12(46), 2013.

[15] M. S. Kramer, "Determinants of Low Birth Weight, Methodological Assessment and Meta-Analysis," Bulletin of the World Health Organization, vol. 65, pp. 663-737, 1987.

[16] van Wijngaarden E., et al., "Prenatal exposure to methylmercury and LCPUFA in relation to birth weight," Ann Epidemiol, vol/issue: 24(4), pp. 273-8, 2014.

[17] Silva D. I., et al., "Association between alcohol abuse during pregnancy and birth weight," Rev Saúde Pública, vol/issue: 45(5), 2011.

[18] Bashore C. J., et al., "Maternal mercury exposure, season of conception and adverse birth outcomes in an urban immigrant community in Brooklyn, New York, U.S.A," Int J Environ Res Public Health, vol/issue: 11(8), pp. 8414-42, 2014.

[19] Mariscal M., et al., "Pattern of alcohol consumption during pregnancy and risk for low birth weight," Ann Epidemiol, vol/issue: 16(6), pp. 432-8, 2006.

[20] start.org, B. "Supporting Change Preventing and addresing alcohol use in pregnancy," 180 Dundasstreet West, Suite 1900 Ontario, Canada: New and Early Child Development Resources Centre, 2005.

[21] Miyake Y., et al., "Alcohol consumption during pregnancy and birth outcomes the Kyushu Okinawa Maternal and Child Health Study," BMC Pregnancy and Childbirth, vol/issue: 14(79), 2014.

[22] Mishra V. and Retherford R. D., "The Effect of Antenatal Care on Professional Assistance at Delivery in Rural India," Population Research and Policy Review, pp. 27307-320, 2008.

[23] Kemenkes, "Pedoman Pelayanan Antenatal Terpadu," Kementerian Kesehatan Direktur Jenderal Bina Kesehatan Masyarakat 2010, Jakarta, 2012.

[24] Oladeinde H. B., et al., "Prevalence and determinants of low birth weight: the situation in a traditional birth home in Benin City, Nigeria," Afr Health Sci., vol/issue: 15(4), pp. 1123-9, 2015.

[25] Asamoah B. O., et al., "Spatial analysis of skilled birth attendant utilization in Ghana," Glob J Health Sci., vol/issue: 6(4), pp. 117-27, 2014.

[26] Dorwie F. M. and Pacquiao D. F., "Practices of traditional birth attendants in Sierra Leone and perceptions by mothers and health professionals familiar with their care," J Transcult Nurs, vol/issue: 25(1), pp. 33-41, 2014.

[27] R. Bixby L., "Spatial access to health care in Costa Rica and its equity: a GIS-based study," Social Science \& 
Medicine, vol/issue: 58(7), pp. 1271-1284, 2004.

[28] Staffan B. S. and Goodburn E., "The Role of Traditional Birth Attendants in the Reduction of Maternal Mortality," Reproductive Health Advisor, Centre for Sexual and Reproductive Health, 2005.

[29] Anderson and Newman, "Guidelines for Growth Charts and Gestational Age Adjustment for Low Birth Weight and Very Low Birth Weight Infants," Precept Press, pp. 33-10, 2005.

[30] de Vocht F., et al., "Maternal residential proximity to sources of extremely low frequency electromagnetic fields and adverse birth outcomes in a UK cohort," Bioelectromagnetics, vol/issue: 35(3), pp. 201-9, 2014.

[31] Dever G. E., "Epidemiology in Health Services Management," USA, An Aspen Publisher, Inc., 1984.

[32] Schuurman N., et al., "Measuring potential spatial access to primary health care physicians using a modified gravity model," Canadian Geographer / Le Géographe Canadien, vol/issue: 54(1), pp. 29-45, 2010.

[33] Jamtsho S., et al., "Spatio-Temporal Analysis of Spatial Accessibility to Primary Health Care in Bhutan," ISPRS Int J Geo-Info, vol/issue: 4(3), pp. 1584-1604, 2015.

[34] de Smith M. J., et al., "Geospatial Analysis A Comprehensive Guide to Principles, Techniques and Software Tools," 2013.

[35] Overmars K. P., et al., "Spatial autocorrelation in multi-scale land use models," Ecological Modelling, vol/issue: 164(2-3), pp. 257-270, 2003.

[36] D. A. Griffith, "Spatial-Autocorrelation," University of Texas at Dallas, Richardson, TX, USA. Elsevier Inc., 2009.

[37] Awini E., et al., "Spatial variations in childhood mortalities at the Dodowa Health and Demographic Surveillance System site of the INDEPTH Network in Ghana," Trop Med Int Health, vol/issue: 15(5), pp. 520-8, 2010.

[38] Shortridge A., "Introduction to Applied Spatial Analysis," Department of Geography, Michigan State University.

[39] Maneewongvatana S. and Mount D. M., "Analysis of Approximate Nearest Neighbor Searching with Clustered Point Sets," American Mathematical Society, 2002.

[40] Dale M. R., et al., "Conceptual and Mathematical Relationships Among Methods for Spatial Analysis," Ecography, pp. 25558-577, 2002

[41] Francis M. R., et al., "Examining spatial patterns in the distribution of Low Birth Weight babies in Southern Indiathe role of maternal, socio-economic and environmental factors," Int J Bio \& Med Research, vol/issue: 3(1), pp. $1255-1259,2012$.

[42] Kulldorff M., "SaTScan_Users_Guide," 2015.

[43] Coleman M., et al., "Using the SaTScan method to detect local malaria clusters for guiding malaria control programmes," Malar J., pp. 868, 2009.

[44] Klug G. M., et al., "Enhanced geographically restricted surveillance simulates sporadic Creutzfeldt-Jakob disease cluster," Brain, vol/issue: 132(Pt 2), pp. 493-501, 2009.

[45] Grady S. C. and Enander H., "Geographic analysis of low birthweight and infant mortality in Michigan using automated zoning methodology," Int J Health Geogr, pp. 810, 2009.

[46] Legerski E. M. and Thayn J. B., "The Effects of Spatial Patterns of Neighborhood Risk Factors on Adverse Birth Outcomes," The Social Science Journal, pp. 50635-645, 2013.

[47] Jamtsho S. and Corner R. J., "Evaluation of spatial accessibility to primary healthcare using GIS," ISPRS Annals of Photogrammetry, Remote Sensing and Spatial Information Sciences, pp. II-279-86, 2014.

[48] Meng G., et al., "Pathways of neighbourhood-level socio-economic determinants of adverse birth outcomes," Int J Health Geogr, pp. 1232, 2013.

[49] Burch J. B., et al., "Mercury in fish and adverse reproductive outcomes: results from South Carolina," Int J Health Geogr, pp. 1330, 2014

[50] Song C. and Kulldorff M., "Power evaluation of disease clustering tests," Int J Health Geogr, vol. 2, 2003.

[51] Anselin L., et al., "GeoDa: An Introduction to Spatial Data Analysis," Spatial Analysis Laboratory Department of Agricultural and Consumer Economics University of Illinois, 2004.

[52] Galvan L., et al., "Rainfall estimation in SWAT: an alternative method to simulate orographic precipitation," $J$ Hydro, pp. 257-265, 2013.

[53] Allamano P., et al., "Global warming increases flood risk in mountainous areas," Geophysical Research Letters, vol/issue: 36(24), 2009.

[54] Nyaken S., "Spatial data analysis as a tool for mineral prospectivity mapping," Geological Survey of Finland, pp. 274, 2008.

[55] Brauer M., et al., "A cohort study of traffic-related air pollution impacts on birth outcomes," Environ Health Perspect, vol/issue: 116(5), pp. 680-6, 2008.

[56] Miranda M. L., et al., "Environmental contributions to disparities in pregnancy outcomes," Epidemiol Rev., pp. 3167-83, 2009.

[57] Asundep N. N., et al., "Determinants of Access to Antenatal Care and Birth Outcomes in Kumasi, Ghana," J Epid Glob Health, vol/issue: 3(4), pp. 279-88, 2013.

[58] Kruk M. E., et al., "Women's preferences for place of delivery in rural Tanzania: a population-based discrete choice experiment," Am J Public Health, vol/issue: 99(9), pp. 1666-72, 2009.

[59] Taylor C. M., et al., "Blood mercury levels and fish consumption in pregnancy: Risks and benefits for birth outcomes in a prospective observational birth cohort," Int J Hyg Environ Health, vol/issue: 219(6), pp. 513-20, 2016.

[60] Marques R. C., et al., "Fish consumption during pregnancy, mercury transfer, and birth weight along the Madeira River Basin in Amazonia," Int J Environ Res Public Health, vol/issue: 10(6), pp. 2150-63, 2013.

[61] Hu X., et al., "Distributions of heavy metals in maternal and cord blood and the association with infant birth weight in China," J Reprod Med., vol/issue: 60(1-2), pp. 21-9, 2015. 
[62] Julian C. G., "High Altitude During Pregnancy," Clinics in Chest Medicine, vol/issue: 32(1), pp. 21-31, 2011.

[63] Candelas N., et al., "Altitude effect on birth weight and prematurity in the Province of Catamarca (Argentina)," $A m$ J Hum Biol., vol/issue: 27(4), pp. 526-9, 2015.

[64] Mortola J. P., et al., "Birth weight and altitude: A study in Peruvian communities," J Pedia, vol/issue: 136(3), pp. 324-329, 2000.

[65] L. Camelo J. S., et al., "Effect of the interaction between high altitude and socioeconomic factors on birth weight in a large sample from South America," Am J Phys Anthropol, vol/issue: 129(2), pp. 305-10, 2006.

[66] Chung M. Y., et al., "Comparison of neonatal outcome for inborn and outborn very low-birthweight preterm infants," Pediatr Int., vol/issue: 51(2), pp. 233-6, 2009.

[67] U. Wort U., et al., "Potential use of birthweight indicators in rural Tanzania for monitoring malaria control in pregnancy," Public Health, vol/issue: 122(9), pp. 923-32, 2008.

[68] Cervigni F., et al., "Spatial accessibility to pediatric services," J Community Health, vol/issue: 33(6), pp. 444-8, 2008.

[69] Attar M. A., et al., "Pregnant mothers out of the perinatal regionalization's reach," J Perinatol, vol/issue: 26(4), pp. 210-4, 2006.

[70] Hebert P. L., et al., "The contribution of geography to black/white differences in the use of low neonatal mortality hospitals in New York City," Med Care, vol/issue: 49(2), pp. 200-6, 2011. 